\title{
AVALIAÇÃO DO DESEMPENHO DE UM CARNEIRO HIDRÁULICO COM TUBULAÇÃO DE ALIMENTAÇÃO EM AÇO GALVANIZADO E EM PVC
}

Caroline abate

Engenheira Agrícola

Orientador: Prof. Dr. TARLEI ARRIEL BOTREL

Dissertação apresentada à Escola Superior de Agricultura "Luiz de Queiroz", Universidade de São Paulo, para a obtenção do título de Mestre em Agronomia, Área de Concentração: Irrigação e Drenagem.

PIR A C I C A B A

Estado de São Paulo - Brasil

Maio - 2000 


\section{ERRATA}

\begin{tabular}{cccc}
\hline página & linha & onde se lề & leia-se \\
\hline 13 & terceira & Marumbi & Marumby \\
32 & primeira & do & de um \\
35 & terceira & NETTO, J.M.deA & AZEVEDO NETTO, J.M. \\
\hline
\end{tabular}


Dados Internacionais de Catalogação na Publicação (CIP)

DIVISĀO DE BIBLIOTECA E DOCUMENTAÇĀO - Campus "Luiz de Oueiroz"/USP

\section{Abate, Caroline}

Avaliação do desempenho de um carmeiro hidráulico com tubulação de alimentaçāo em aço galvanizado e em PVC / Caroline Abate. - - Piracicaba, 2000

35 p. : il.

Dissertação (mestrado) - - Escola Superior de Agricultura Luiz de Queiroz, 2000.

Bibliografia.

1. Bomba hidráulica 2. Energia elétrica 3. Hidráulica agrícola 4. Tubo de aço 5. Tubo de PVCI. Título

CDD 631.7

"Permitida a cópia total ou parcial deste documento, desde que citada a fonfe = 0 autor" 


\section{AGRADECIMENTOS}

Meus sinceros agradecimentos a todas as pessoas e instituições que, de forma direta ou indireta, contribuíram para a consecução deste trabalho. Em especial, agradeço:

Ao Prof. Dr. Tarlei Arriel Botrel, pela sempre presente orientação e apoio;

A CAPES - Fundação Coordenação de Aperfeiçoamento de Pessoal de Nível Superior, pela concessão da bolsa de estudo;

Aos professores José Antônio Frizzone e Antônio Sanches de Oliveira pela colaboração técnica.

Aos funcionários do Laboratório de Hidráulica e Irrigação, Antônio, César e Hélio, pela ajuda prestada durante a implantação e condução dos ensaios;

Aos colegas Cecilia, Davilmar, Edivânia, Gersio, Patricia, Rene, Ronaldo e Valdemício;

Às amigas Cristina e Rosa por momentos inesquecíveis em minha vida.

À Tamara que foi minha companheira de sala, minha revisora de dissertação e o mais importante, uma amiga; e

Aos meus pais, pela sempre presença em minha vida e pelo apoio dado em todo 0 período de estudo. 


\section{SUMÁRIO}

Página

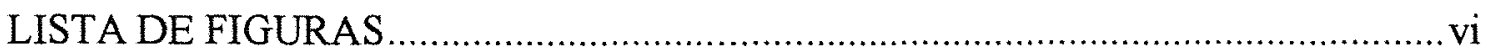

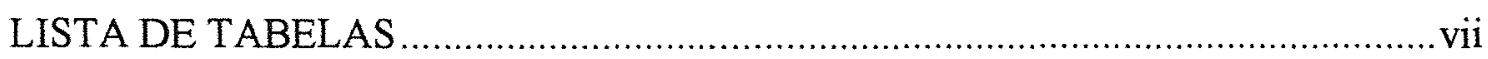

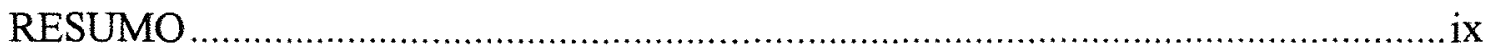

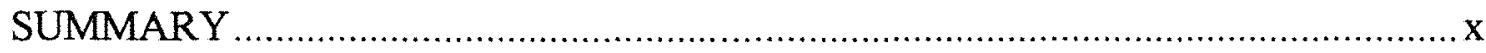

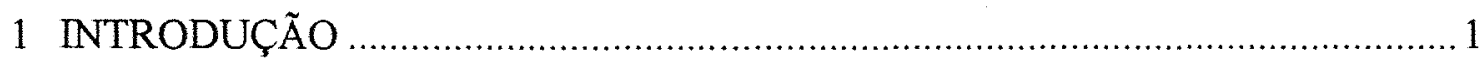

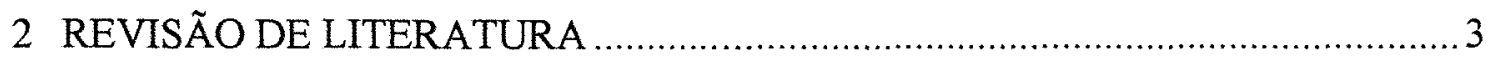

2.1 Constituição e princípio de funcionamento de um carneiro hidráulico ...................3

2.1.1 Partes constituintes de um carneiro hidráulico .............................................. 5

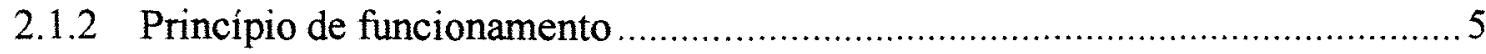

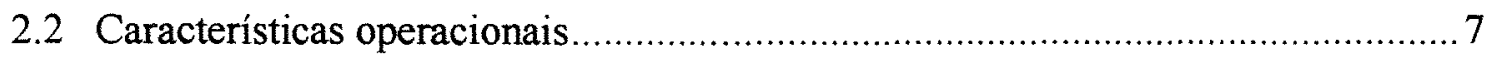

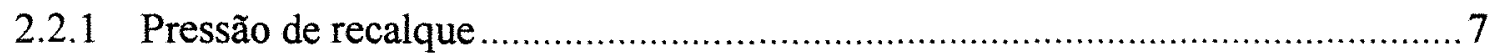

2.2.2 Desnível entre o reservatório de alimentação e o carneiro hidráulico .................8

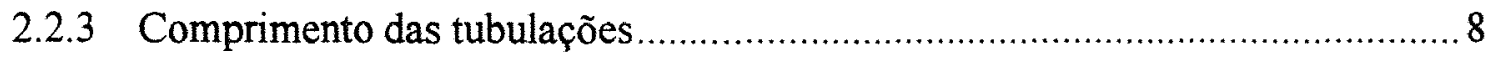

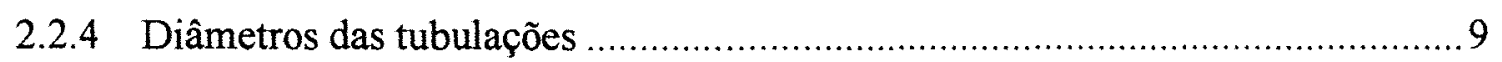

2.2.5 Material constituinte da tubulação de alimentação ......................................... 9

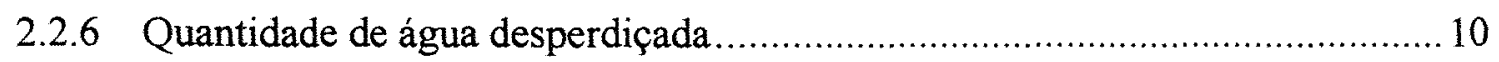

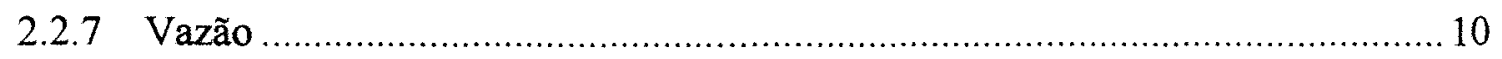

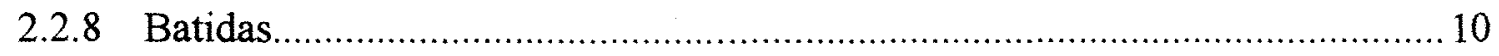

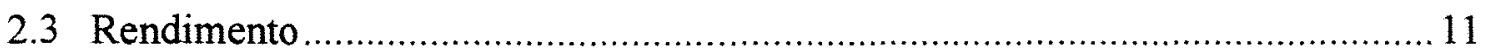

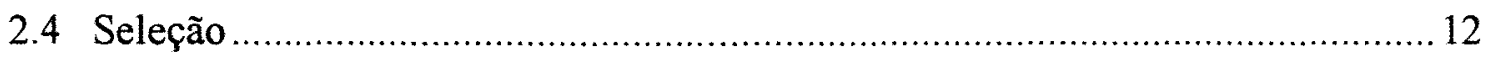

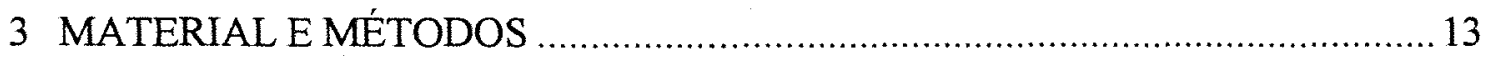

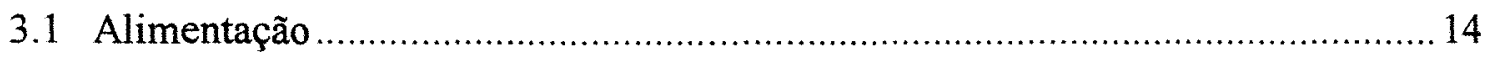

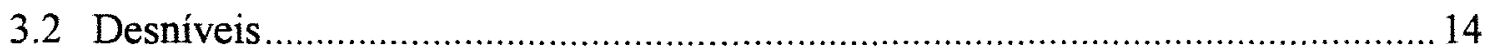

3.3 Comprimento e diâmetro da tubulação de alimentação …………….................... 15

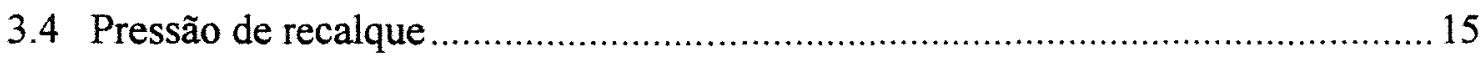

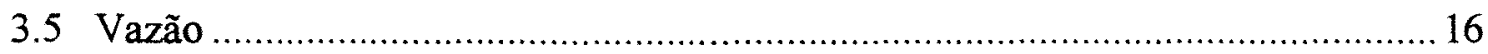

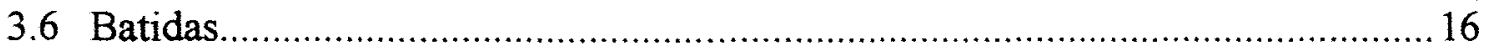

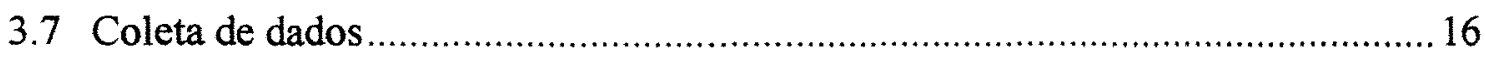




\section{Página}

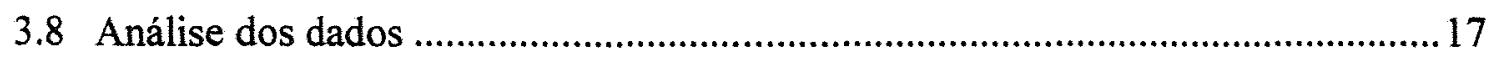

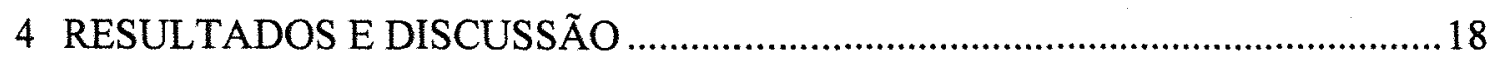

4.1 Influência dos materiais constituintes da tubulação de alimentação .....................18

4.2 Frequência de batidas da válvula de escape ...........................................................23

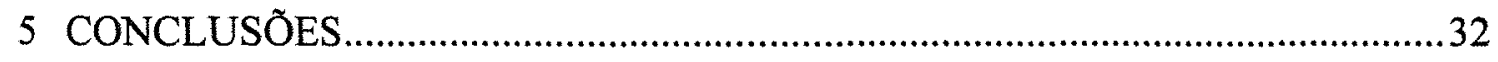

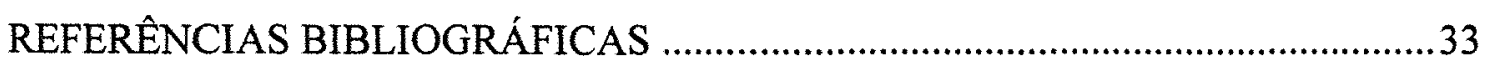




\section{LISTA DE FIGURAS}

Página

1 Esquema de um carneiro hidráulico original.....................................................

2 Esquema de um carneiro hidráulico moderno ...........................................................

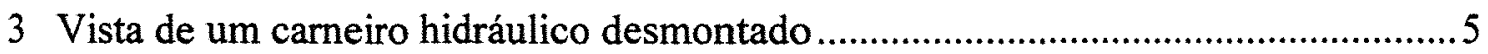

4 Esquema funcional de um carneiro hidráulico ............................................................

5 Esquema de montagem do experimento................................................................13

6 Esquema dos desníveis de alimentação adotados ..................................................15

7 Rendimento e pressão em função da vazão e do desnível da tubulação de alimentação e do material constituinte ......................................................................... 19

8 Rendimento $v s$ desnível para os materiais estudados...............................................21

9 Rendimento e pressão em função da vazão e do desnível da tubulação de alimentação e do material constituinte .......................................................................24 


\section{LISTA DE TABELAS}

Página

1 Parâmetros da equação de regressão rendimento vs vazão 20

2 Rendimento máximo, pressão e vazão de recalque correspondentes para os desníveis e materiais estudados

3 Parâmetros da equação de regressão pressão vs vazão 22

4 Pressão máxima para os desníveis e materiais estudados 23

5 Parâmetros da equação de regressão de rendimento vs vazão para desnivel de 2,1 m e material da tubulação de aço galvanizado

6 Parâmetros da equação de regressão de pressão vs vazão para desnível de 2,1 m e material da tubulação de aço galvanizado .25

7 Rendimento máximo, vazão e pressão para o rendimento máximo, utilizando tubulação de aço com desnível de $2,1 \mathrm{~m}$

8 Parâmetros da equação rendimento $v s$ vazão para desnível de $2,1 \mathrm{~m}$ e

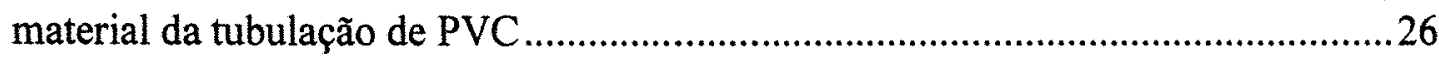

9 Parâmetros da equação de regressão de pressão vs vazão para desnível de 2,1 m e material da tubulação de PVC

10 Rendimento máximo, vazão e pressão para o rendimento máximo, utilizando tubulação de PVC com desnível de $2,1 \mathrm{~m}$..............................................26

11 Parâmetros da equação rendimento vs vazão para desnível de $3,8 \mathrm{~m}$ e material da tubulação de aço galvanizado.

12 Parâmetros da equação de regressão de pressão vs vazão para desnivel de $3,8 \mathrm{~m}$ e material da tubulação de aço galvanizado

13 Rendimento máximo, vazão e pressão para o rendimento máximo, utilizando tubulação de aço com desnivel de $3,8 \mathrm{~m}$

14 Parâmetros da equação rendimento $v s$ vazão para desnivel de $3,8 \mathrm{~m}$ e material da tubulação de PVC

15 Parâmetros da equação pressão $v s$ vazão para desnivel de 3,8 m e material da tubulação de PVC 
Página

16 Rendimento máximo, vazão e pressão para o rendimento máximo, utilizando tubulação de PVC com desnível de $3,8 \mathrm{~m}$

17 Parâmetros da equação rendimento vs vazão para desnível de $4,7 \mathrm{~m} \mathrm{e}$ material da tubulação de aço galvanizado

18 Parâmetros da equação de regressão de pressão vs vazão para desnível de

4,7 m e material da tubulação de aço galvanizado.

19 Rendimento máximo, vazão e pressão para o rendimento máximo, utilizando tubulação de aço com desnível de 4,7 m

20 Parâmetros da equação rendimento vs vazão para desnível de $4,7 \mathrm{~m}$ e material da tubulação de PVC.

21 Parâmetros da equação de regressão de pressão vs vazão para desnível de 4,7 m e material da tubulação de PVC 30

22 Rendimento máximo, vazão e pressão para o rendimento máximo, utilizando tubulação de PVC com desnível de 4,7 m 30 


\title{
AVALIAÇÃO DO DESEMPENHO DE UM CARNEIRO HIDRÁULICO COM TUBULAÇÃO DE ALIMENTAÇÃO EM AÇO GALVANIZADO E EM PVC
}

\author{
Autora: CAROLINE ABATE \\ Orientador: Prof. Dr. TARLEI ARRIEL BOTREL
}

\section{RESUMO}

Este experimento foi desenvolvido no Laboratório de Hidráulica do Departamento de Engenharia Rural - USP/ESALQ, com o objetivo de avaliar o desempenho de um carneiro hidráulico para dois tipos de materiais diferentes na tubulação de alimentação, PVC e aço galvanizado sob três alturas de queda $(2,1 \mathrm{~m}, 3,8$ m e 4,7 m). Foi utilizado a equação de D'Aubuisson para o cálculo do rendimento, sendo calculado a partir das leituras de pressão de recalque, vazão de escape, vazão de recalque e altura de alimentação. Para a representação dos dados, utilizou-se equação polinomial de segundo grau para as curvas de rendimento e equação exponencial para as curvas de pressão. Verificou-se que pode-se conseguir o rendimento máximo com o carneiro hidráulico utilizando-se de tubulação alimentadora de PVC com até 4,2 m de desnível; além desse valor a tubulação de aço galvanizado é mais eficiente; e há influência do número de batidas no desempenho de um carneiro hidráulico. 


\title{
EVALUATE THE PERFORMANCE OF A HYDRAULIC RAM UTILIZING PVC SUPPLY PIPE AND STEEL SUPPLY PIPE
}

\author{
Author: CAROLINE ABATE \\ Adviser: Prof. Dr. TARLEI ARRIEL BOTREL
}

\section{SUMMARY}

This experiment was carried out in the Laboratory of Hydraulic at USP/ESALQ and the objective was to evaluate the performance of the hydraulic ram pump utilizing two kinds of materials in the supply pipe (PVC and steel) in three different supply heads $(2.1 \mathrm{~m}, 3.8 \mathrm{~m}$ and $4.7 \mathrm{~m})$. Delivery head and discharge, waste discharge and supply head were utilized to calculate the yield of the hydraulic ram by D'Aubuisson's equation. The maximum yield of the hydraulic ram can be obtained when the PVC pipe is utilized with $4.2 \mathrm{~m}$ of supply head; more than $4.2 \mathrm{~m}$, the steel pipe gives more efficiency; and the performance of the hydraulic ram influences the number of beats of the waste valve. 


\section{INTRODUÇÃo}

A crise da energia convencional tem ocasionado a exploração de fontes de energias alternativas para suprir usos doméstico, industrial e agrícola (Bhoi et al., 1994).

$O$ bombeamento utilizando carneiro hidráulico é amplamente empregado em muitas propriedades, principalmente onde a energia elétrica é inexistente. Apresenta as vantagens de não necessitar de energia elétrica, manutenção barata e simples e não exigir mão-de-obra qualificada. A fonte de energia é a altura de queda d'água, que em geral é produzida por meio de pequena barragem.

O carneiro hidráulico ou ariete hidráulico é uma máquina simples, que possui características geratriz e operatriz (MacIntyre, 1980). Seu funcionamento é decorrente do golpe de ariete causado pelo fechamento de uma válvula, que interrompe o movimento da água proveniente de uma fonte de alimentação localizada em nível superior.

Os custos com manutenção são mínimos, visto que as partes móveis são constituídas de materiais resistentes e duráveis. Fabricantes e autores como: Lifewater, 2000; BC Livestock Watering, 2000; Marumby; Daker, 1970, recomendam a utilização de aço galvanizado na tubulação de alimentação, mas com a popularização do PVC, este apresenta vantagens sobre o aço galvanizado como menor custo e facilidades para a instalação. Procurando dar subsídios técnicos a utilização do PVC nos sistemas de alimentação, este trabalho teve como objetivo avaliar o desempenho de um carneiro hidráulico quando alimentado por tubulação constituída de PVC e de aço galvanizado sob três alturas diferentes de alimentação. 


\section{REVISÃO DE LITERATURA}

As máquinas de fluido incompressivel são dispositivos que permitem intercâmbio de energia entre as partes mecânicas móveis e o fluido incompressível em escoamento. No caso em que a energia armazenada pelos fluidos que escoam, transforma-se em energia mecânica, tem-se máquinas motoras, geralmente chamadas motores ou turbinas. Quando a conversão é feita no sentido inverso tem-se as máquinas movidas, chamadas particularmente de bombas. Carneiro hidráulico é uma máquina resultante do acoplamento íntimo de uma máquina motora com uma movida (Zambel, 1969).

Fleming (2000), descreve a evolução do carneiro hidráulico: John Whitehurst em 1772 inventou o carneiro hidráulico na Inglaterra, porém com o acionamento da válvula feito manualmente. Em 1796 o francês, Joseph Michael Montgolfier adicionou uma válvula de escape com acionamento próprio, passando a ser uma máquina com movimentos "contínuos", em situações em que o suprimento de água fora equilibrado. Em 1809 surge a primeira patente americana por J. Cerneau e S. S. Hallet em Nova York. A partir de 1832 a informação começou a ser divulgada no leste dos Estados Unidos como "bomba simples que empurra água para cima usando energia da queda d'água". O primeiro carneiro foi construído inteiramente em madeira e rapidamente evoluindo para o construído em ferro. Artigos em revistas como Farmer's Cabinet e Famer trouxeram novos reconhecimentos e entendimentos do carneiro hidráulico e um livro detalhado foi publicado em 1842. Em 1879 a enciclopédia People incluiu o carneiro hidráulico na média das 55 mais importantes invenções da história. Definindo o carneiro como: "Um simples e conveniente mecanismo, que pela altura da queda d'água 
pode ser elevada uma parte da água para uma altura considerável".

O custo do carneiro hidráulico foi a maior vantagem no crescimento de sua utilização, não somente por ser uma máquina de baixo custo, mas fácil de instalar, sem requerer muita técnica para operação.

Destacam-se como vantagens: custo de aquisição baixo, pode ser instalado no tempo, não necessita de casa de bombas, não precisa de filtro, não utiliza energia elétrica para seu acionamento, pode ser utilizado 24 horas por dia, bombea sem emissão de poluentes ou gases (Horne \& Newman, 2000), energia de alimentação é livre e renovável, excelente para grandes distâncias, não utiliza motor e custos de operação são baixos (BC Livestock Watering, 2000). Como desvantagens: eficiência é determinada pelas condições locais e golpe de ariete é barulhento.

O carneiro hidráulico utiliza-se do golpe de aríete para seu funcionamento. $O$ fenômeno do golpe de aríete é de natureza complexa, cuja determinação é importante para a aplicação de medidas preventivas em sistemas de recalque (Netto, 1969).

MacIntyre (1980) afirma que o golpe de ariete é uma sobrepressão que ocorre em um líquido em escoamento, quando, por qualquer razão, a descarga é submetida a uma repentina variação ou mesmo impedida de se processar. A sobrepressão se transmite para o próprio líquido e deste às paredes do encanamento.

Durante o ciclo de recalque, as ondas de pressão "sobem e descem" através da tubulação de alimentação entre o reservatório de alimentação e o carneiro hidráulico. Séries de golpes de aríete ocasionam redução excessiva da velocidade da água na tubulação de alimentação (Kitani \& Willardson,1984).

\subsection{Constituição e princípio de funcionamento de um carneiro hidráulico}

O carneiro hidráulico é uma máquina compacta constituída por um corpo de ferro fundido e válvulas. Já existem carneiros hidráulicos que são fabricados em plástico reforçado com fibra de vidro (Carrasco, 2000). 
Comparando o carneiro hidráulico original com o moderno verifica-se que ambos utilizam o mesmo princípio de funcionamento, diferenciando-se apenas no tipo da válvula de escape e na inclinação da canalização de alimentação (Horne \& Newman, 2000). Nas Figuras 1 e 2 são apresentados os esquemas dos carneiros hidráulicos original e moderno.

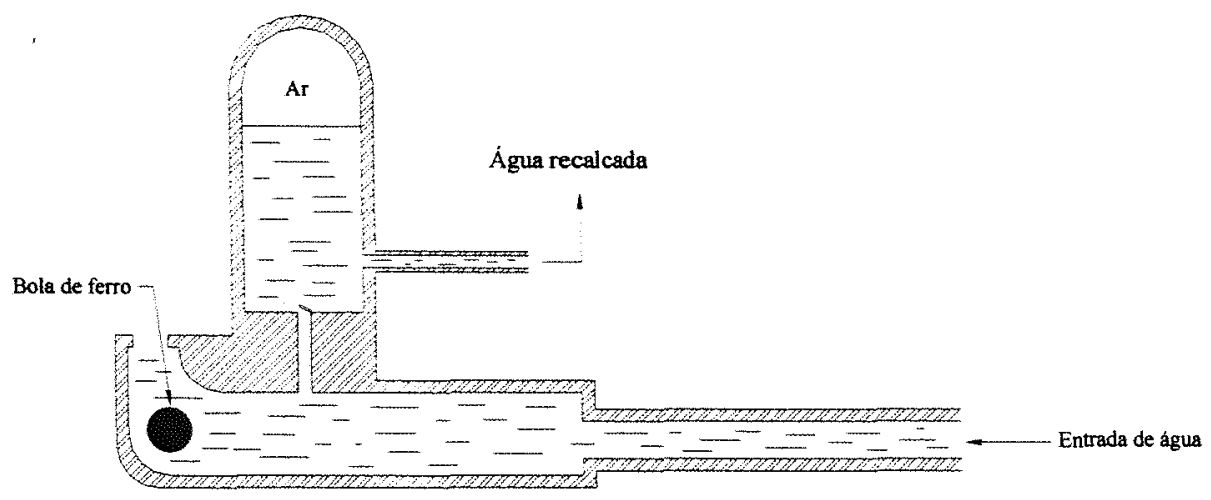

Figura 1- Esquema de um carneiro hidráulico original

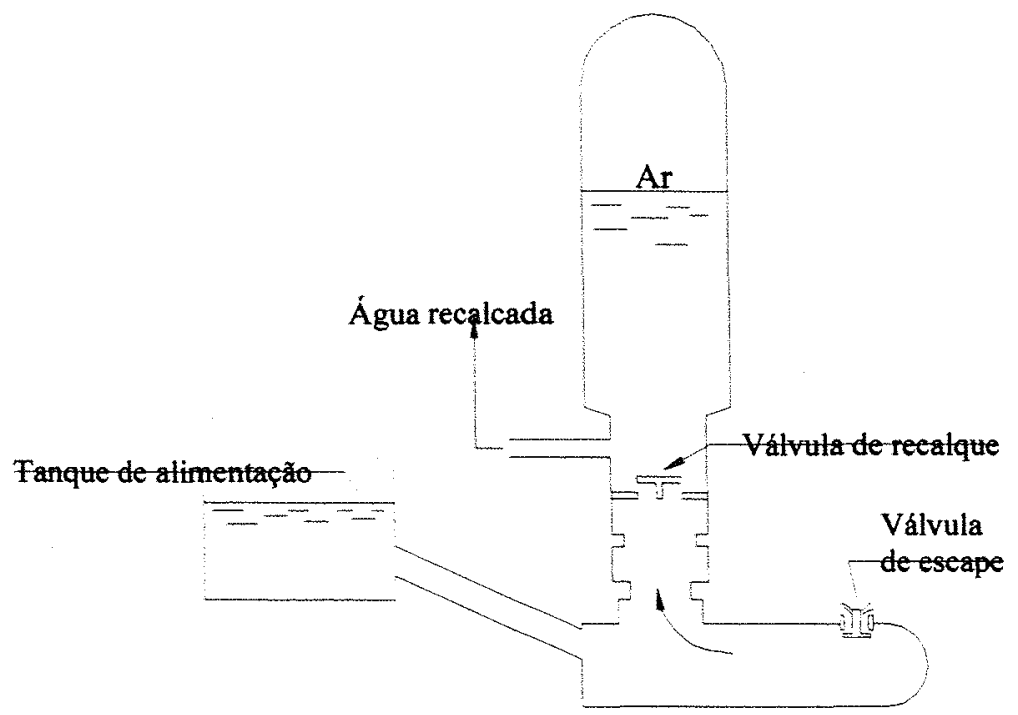

Figura 2- Esquema de um carneiro hidráulico moderno 


\subsubsection{Partes constituintes de um carneiro hidráulico}

O carneiro hidráulico é constituído por partes fixas e móveis. As partes fixas são: base, campânula e castelo. As partes móveis são: válvula de escape que é constituída de liga metálica apropriada para propiciar maior vida útil, e a válvula de recalque, revestida de couro ou borracha.

Na Figura 3 apresenta-se uma vista geral de um carneiro hidráulico desmontado.
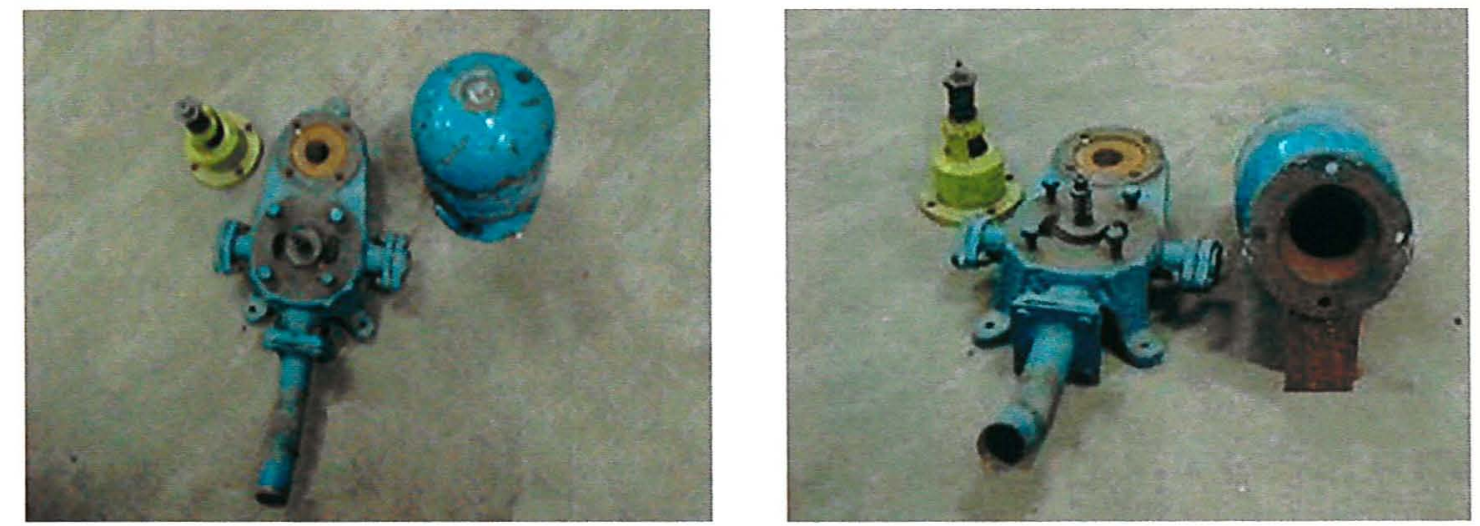

Figura 3- Vista de um carneiro hidráulico desmontado

\subsubsection{Princípio de funcionamento}

Na Figura 4, mostra-se um esquema funcional de um carneiro hidráulico de acordo com os princípios apresentado por Daker (1970): 


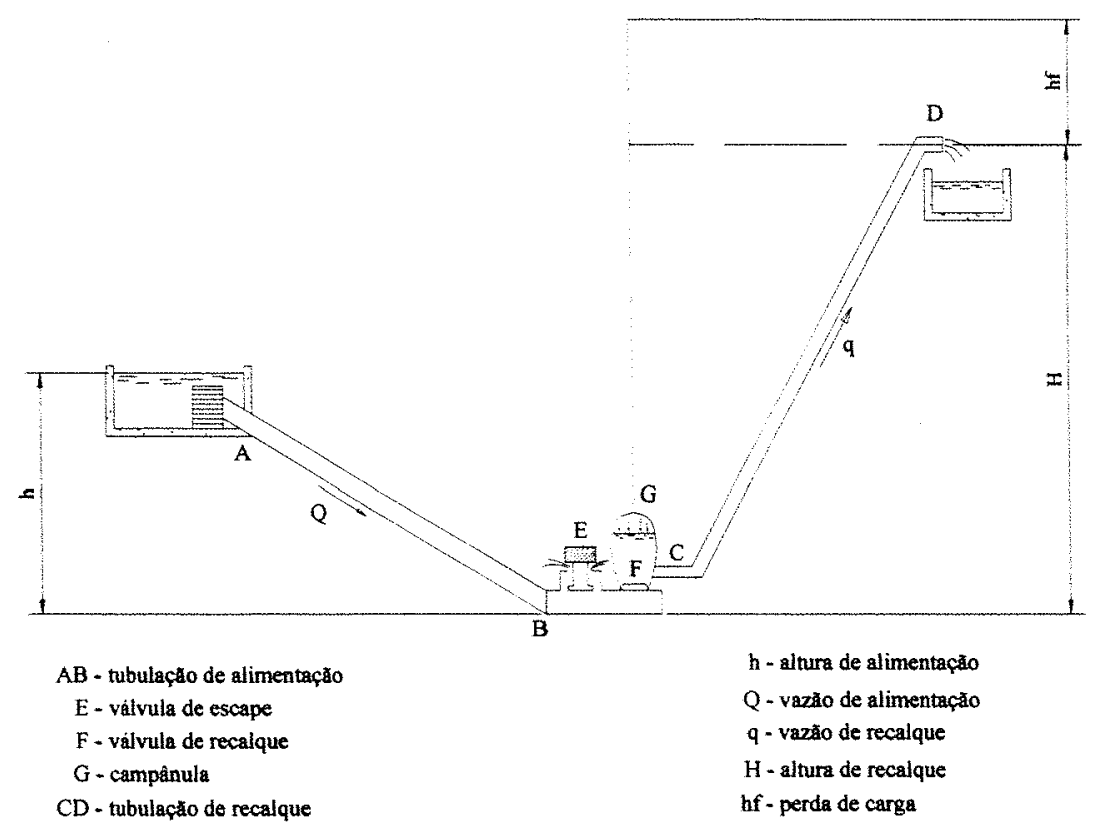

Figura 4- Esquema funcional de um carneiro hidráulico

Estando aberta a válvula $\mathrm{E}$, a água, conduzida $(\mathrm{Q})$ de um ponto mais alto pelo tubo de alimentação $A B$, escapa por ela até que a pressão, em virtude da velocidade crescente do líquido, torna-se capaz de erguê-la, fechando-a bruscamente. A água desce pelo tubo $\mathrm{AB}$ com velocidade progressiva, ficando num dado instante sem saída, produzindo o choque denominado "golpe de aríete", o qual abre a válvula de recalque $\mathrm{F}$, permitindo a entrada da água na câmara de ar G. Como decorrência, o ar existente na parte superior da campânula é comprimido e oferece uma resistência crescente à entrada do líquido, chegando a tal ponto de faze-la cessar, fechando-se, neste instante, a válvula F. A seguir haverá produção de uma onda de pressão negativa em virtude do efeito da compressibilidade da água e da elasticidade da tubulação que atua na válvula $\mathrm{E}$, fazendo-a abrir novamente. Estando $E$ aberta, haverá um novo ciclo e, com ciclos sucessivos, a água que vai penetrando na câmara de ar $\mathrm{G}$, vai tendo pressão para subir na tubulação de recalque $\mathrm{CD}$, fazendo com que flua (q) para o reservatório superior quando a pressão na campânula corresponder à atura manométrica de recalque.

Roos et al. (2000), separam o ciclo de funcionamento de um carneiro hidráulico em 3 etapas: a) aceleração - quando a válvula de escape se abre, a água ganha 
velocidade até que a fecha bruscamente; b) recalque - por fração de segundos, a água entra na campânula e comprime o ar; como a válvula de recalque dentro da campânula tem um único sentido, a água segue para a tubulação de recalque e a válvula de escape reabre com a redução da pressão na campânula; e c) recolhimento - a água vai para a tubulação de recalque. Cessando a pressão da campânula, a água adquire velocidade na tubulação de alimentação e flui através da válvula de escape, iniciando um novo ciclo.

$\mathrm{O}$ número de ciclos por minuto difere entre carneiros hidráulicos. Jennings (1996) descreve que o ciclo se repete entre 20 e 100 por minuto, dependendo da razão entre as vazões de alimentação e de recalque. Já Kitani \& Willardson (1984) descrevem que o ciclo se repete com uma frequiência de 30 a 100 por minuto, dependendo da construção do carneiro e dos ajustes.

\subsection{Características operacionais}

São definidas como características operacionais de um carneiro hidráulico: pressão de recalque, desnível entre o reservatório de alimentação e o carneiro hidráulico, comprimento das tubulações, diâmetro das tubulações, material constituinte da tubulação de alimentação, quantidade de água desperdiçada, vazão, batidas por minuto e rendimento.

\subsubsection{Pressão de recalque}

A altura de elevação da água depende do carneiro hidráulico utilizado e das condições de instalação do mesmo. Corvalán \& Gálvez (2000) encontraram $300 \mathrm{~m}$ de pressão de recalque para o carneiro hidráulico que tem $0,51 \mathrm{~m}$ de diâmetro na tubulação de alimentação e eleva cerca de $0,06 \mathrm{~m}^{3} \cdot \mathrm{s}^{-1}$, Jennings (1996) encontrou $120 \mathrm{~m}$ de pressão de recalque para um carneiro hidráulico com vazão de $3,15.10^{-3} \mathrm{~m}^{3} \cdot \mathrm{s}^{-1}$ e BC Livestock Watering (2000) relacionou a pressão de recalque $(\mathrm{H})$ com a altura de alimentação (h): $\mathrm{H}=6 \mathrm{a} 12 \mathrm{~h}$. 


\subsubsection{Desnível entre o reservatório de alimentação e o carneiro hidráulico}

Para o funcionamento de um carneiro hidráulico a fonte de energia é a potencial, a qual é convertida em energia cinética dentro da tubulação (Das et al., 1989). Há um limite tolerável de desnivel geométrico entre o reservatório de alimentação e o carneiro hidráulico.

Bhoi et al. (1994) afirmam que o fator de grandeza é a razão entre pressão de recalque $(\mathrm{H})$ e altura de alimentação $(\mathrm{h})$, ou seja,

$$
f=\frac{H}{h}
$$

Uma das características que mais variam na literatura e com os fabricantes é o limite de desnível mínimo e máximo entre o reservatório de alimentação e o carneiro hidráulico. Dentre os desníveis mínimos, foram encontrados de $0,45 \mathrm{~m}$ (Aqua Environment Co, 1997) a $2 \mathrm{~m}$ (Jeffery, 1992). Por exemplo: 0,5 m (Horne \& Newman, 2000; BC Livestock Watering, 2000; e Lifewater International, 2000), 0,6 m (Griffin, 2000), 1 m (Thomas, 1994; Corvalán \& Gálvez, 2000; Jennings, 1996; Daker, 1970; Lifewater, 2000; Marumby; e Roos et al., 2000). Os máximos desníveis encontrados foram de 7,5 m (Aqua Environment Co, 1997) e $9 \mathrm{~m}$ (Daker, 1970).

\subsubsection{Comprimento das tubulações}

O comprimento da tubulação de alimentação recebe diferentes recomendações: 5 a 10 vezes a altura de alimentação (BC Livestock Watering, 2000); 8 até 12 vezes a altura de alimentação para desníveis maiores que $3 \mathrm{~m}$ e de 5 até 8 vezes a altura de alimentação para desniveis entre 3 e 7,5 m (Aqua Environment Co, 1997); pelo menos 5 vezes a altura da alimentação (Jennings, 1996); 4 a 6 vezes a altura de alimentação (Lifewater International, 2000); e 6 a 12 vezes a altura de alimentação (Kitani \& Willardson, 1984 e Krol, 1976). 
Para um desempenho eficiente do carneiro hidráulico, Calvert ${ }^{1}$ citado por Kitani \& Willardson (1984) indica que a razão entre o comprimento e o diâmetro da tubulação de alimentação deve ser de 150 até 1000 .

Jennings (1996) afirma que o comprimento da tubulação de recalque geralmente é considerado de pouca importância para a instalação, pois a perda de carga por atrito é reduzida em função da pequena vazão.

\subsubsection{Diâmetros das tubulações}

Corvalán \& Gálvez (2000) menciona que o diâmetro da tubulação de alimentação varia entre 0,05 e $0,5 \mathrm{~m}$, enquanto Horne \& Newman (2000) afirmam que o diâmetro da tubulação de alimentação varia de 0,025 a $0,1 \mathrm{~m}$ e o da tubulação de recalque varia entre 0,04 e $0,05 \mathrm{~m}$, com 1 ou $2 \mathrm{~m}$ de desnivel. Lifewater International (2000) recomenda que a tubulação de alimentação tenha no mínimo uma unidade de diâmetro maior que o da tubulação de recalque.

\subsubsection{Material constituinte da tubulação de alimentação}

$O$ material da tubulação de alimentação afeta o desempenho do carneiro. $O$ módulo de elasticidade da tubulação causa significativas mudanças na elevação da pressão originada pelo golpe de aríete, decorrente da mudança de velocidade da onda de pressão na tubulação (Kitani \& Willardson,1984).

A Lifewater International (2000) afirma que a tubulação de alimentação deve ser constituída de material pouco flexível para a máxima eficiência; geralmente utilizase tubulação de aço galvanizado, ao invés de plástico, devido ao efeito do golpe de aríete (BC Livestock Watering, 2000). Entretanto Kitani \& Willardson (1984) recomendam o

\footnotetext{
${ }^{1}$ CALVERT, N.G. Drive pipe of a hydraulic ram. The Engineer, v.206 n.5390, p.1001, 1958.
} 
uso de PVC na tubulação de alimentação para recalque até $22,9 \mathrm{~m}$ ou 6 vezes menor ou igual a altura de alimentação.

\subsubsection{Quantidade de água desperdiçada}

Horne \& Newman (2000) afirmam que aproximadamente $3 / 4$ da água que passa através do sistema sai pela válvula de escape. Linsley et al.(1992) observaram que a razão entre a quantidade de água desperdiçada e bombeada é de 2:1 até 6:1.

\subsubsection{Vazão}

Alguns valores de vazão para carneiros hidráulicos são apresentados por diversos autores e fabricantes: Jennings (1996), encontrou vazão máxima de recalque de $0,0032 \mathrm{~m}^{3} \cdot \mathrm{s}^{-1}$ para um carneiro hidráulico que recalca $120 \mathrm{~m}$ de altura e possui tubulação de alimentação com $0,152 \mathrm{~m}$ de diâmetro, Corvalán \& Gálvez, (2000) encontraram vazão de $0,06 \mathrm{~m}^{3} \cdot \mathrm{s}^{-1}$ para um carneiro hidráulico com tubulação de alimentação de 0,51 m de diâmetro e com pressão de recalque de $300 \mathrm{~m}$; Thomas (1994) e BC Livestock Watering (2000) afirmam que $10 \%$ da vazão de alimentação é recalcada e Lifewater (2000) que, dependendo do desnivel entre alturas de alimentação e recalque, poderá elevar-se de $1 \%$ a $20 \%$ da vazão de alimentação.

\subsubsection{Batidas}

Refere-se ao som emitido quando a válvula de escape se fecha, depois de completar um ciclo de operação (Bhoi et al., 1994). O número de batidas varia em função da condição de operação e regulagem feita na válvula de escape. A regulagem é feita aumentando ou diminuindo o curso da mesma, obtendo-se o máximo de rendimento do carneiro para cada condição de instalação. 
Para menor número de batidas por minuto, desenvolve-se maior pressão, consequentemente recalca-se maior vazão por batida. É conveniente ensaiar, em cada instalação, vários números de batidas e selecionar aquela que proporciona o melhor rendimento ou a maior vazão de recalque.

\subsection{Rendimento}

$\mathrm{Lal}^{2}$ citado por Das et al. (1989) demonstra três formas de calcular o rendimento de um carneiro hidráulico: Rendimento volumétrico: razão entre a vazão recalcada e vazão total de água, eq. (2); Rankine: razão entre o produto da vazão recalcada pela diferença de nível entre alimentação e recalque e pelo produto da vazão de alimentação e a altura correspondente, eq. (3); D'Aubuisson: razão da vazão de recalque multiplicada pela pressão de recalque e vazão total de alimentação multiplicada pela altura de alimentação, eq. (4).

$$
\begin{aligned}
& \eta=\frac{q}{(Q+q)} \cdot 100 \\
& \eta=\frac{q \cdot(H-h)}{Q \cdot h} \cdot 100 \\
& \eta=\frac{q \cdot H}{(Q+q) \cdot h} \cdot 100 \\
& \text { sendo: } \\
& \eta-\text { rendimento, \% } \\
& q \text { - vazão recalcada, } \mathrm{m}^{3} \cdot \mathrm{s}^{-1} \\
& Q \text { - vazão recolhida na válvula de escape, } \mathrm{m}^{3} \cdot \mathrm{s}^{-1} \\
& \mathrm{~h} \text { - altura de alimentação, } \mathrm{m} \\
& \mathrm{H} \text { - altura recalcada, } \mathrm{m}
\end{aligned}
$$

\footnotetext{
${ }^{2}$ LAL, J. Hydraulic machine. New Delhi: Metropolitan Book Company. 1981
} 
As equações de D'Aubuisson e Rankine são mais utilizadas; Kitani \& Willardson (1984) afirmam que a equação de Rankine apresentam valores ligeiramente menores que a equação de D'Aubuisson.

Diferentes valores de rendimentos foram encontrados na literatura: MacIntyre (1980) afirma que este valor está entre $50 \%$ e $80 \%$, Thomas (1994), entre 50 e $75 \%$; Jennings, (1996) em torno de $60 \%$ e Slack $^{3}$ et al. citado por Kitani \& Willardson (1984) destacam que para carneiros comerciais está em torno de $60 \%$ e, para carneiros nãocomerciais de $80 \%$.

\subsection{Seleção}

A capacidade ou tamanho do carneiro hidráulico refere-se à vazão de água de entrada, não levando em consideração o recalque; cada carneiro hidráulico necessita de uma vazão mínima e máxima para seu bom funcionamento (Zanini \& Beduschi, 1991). Fabricantes afirmam que vários fatores devem ser considerados para a seleção do tamanho do carneiro hidráulico: vazão de alimentação $\left(\mathrm{m}^{3} \cdot \mathrm{s}^{-1}\right)$, que deve ser verificada no período mais seco do ano; desnivel entre o reservatório de alimentação e o carneiro hidráulico $(\mathrm{m})$; pressão de recalque $(\mathrm{m})$; vazão de recalque $\left(\mathrm{m}^{3} \cdot \mathrm{s}^{-1}\right)$; e comprimento da tubulação de recalque $(\mathrm{m})$. Podem ser usados carneiros hidráulicos associados em paralelo quando a quantidade de água não for suficiente para atender a demanda (Lifewater International, 2000).

\footnotetext{
${ }^{3}$ SLACK, D.C.; BURKANS, T.H.; ESHENAUR, W.C. Theoretical and experimental characteristics of the water pumping hydraulic ram. St. Joseph: ASAE paper 82-5537. 1982.
} 


\section{MATERIAL E MÉTODOS}

O experimento foi desenvolvido no Laboratório de Hidráulica do Departamento de Engenharia Rural da ESALQ/USP. Empregou-se um carneiro hidráulico Marumbi, número 4 com diâmetro de entrada de $0,038 \mathrm{~m} \mathrm{(1} \mathrm{1/2")} \mathrm{e} \mathrm{de} \mathrm{saída}$ de $0,019 \mathrm{~m}(3 / 4 ")$.

O esquema da montagem do experimento para os ensaios realizados é apresentado na Figura 5.

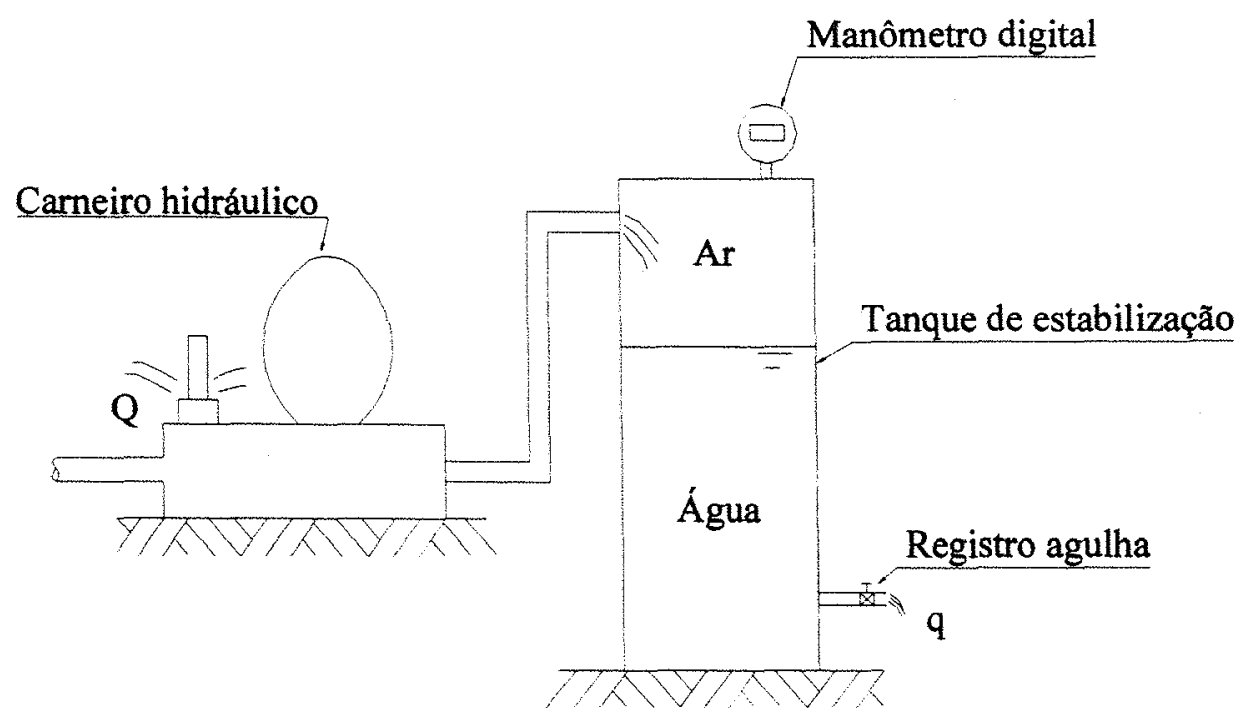

Figura 5- Esquema de montagem do experimento 


\subsection{Alimentação}

Como reservatório de alimentação utilizou-se um tanque de $0,2 \mathrm{~m}^{3}$, com um dreno situado na metade da sua altura, fazendo com que o tanque permanecesse com 0,1 $\mathrm{m}^{3}$ de água em nível constante. Uma bomba centrífuga KSB, modelo ETA 50-26, vazão de $6,9 \times 10^{-3} \mathrm{~m}^{3} \cdot \mathrm{s}^{-1}$, altura manométrica de $250 \mathrm{kPa}$, potência instalada de $3,7 \mathrm{~kW}$, e $1710 \mathrm{rpm}$ foi utilizada para a alimentação desse tanque. Parte da água bombeada foi conduzida para a tubulação de alimentação e a água em excesso retornava através de um dreno para o reservatório abastecedor.

\subsection{Desníveis}

De acordo com as condições locais, foram adotados 3 desníveis entre o reservatório de alimentação e o carneiro hidráulico: $2,1 \mathrm{~m}, 3,8 \mathrm{~m}$ e 4,7 m. Esses desníveis foram obtidos aumentado e abaixando o carneiro hidráulico e/ou o reservatório de alimentação, ficando o carneiro hidráulico bem fixado na base.

Para se obter a posição 1 (desnível de $2,1 \mathrm{~m}$ ), colocou-se o carneiro hidráulico na maior altura e o reservatório de alimentação na menor altura possível; para a posição 2 (desnivel de $3,8 \mathrm{~m}$ ), tanto o reservatório como o carneiro hidráulico foram posicionados na maior altura; e para a posição 3 (desnivel de $4,7 \mathrm{~m}$ ), colocou-se o carneiro hidráulico na menor altura e o reservatório de alimentação na maior (Figura 6). 


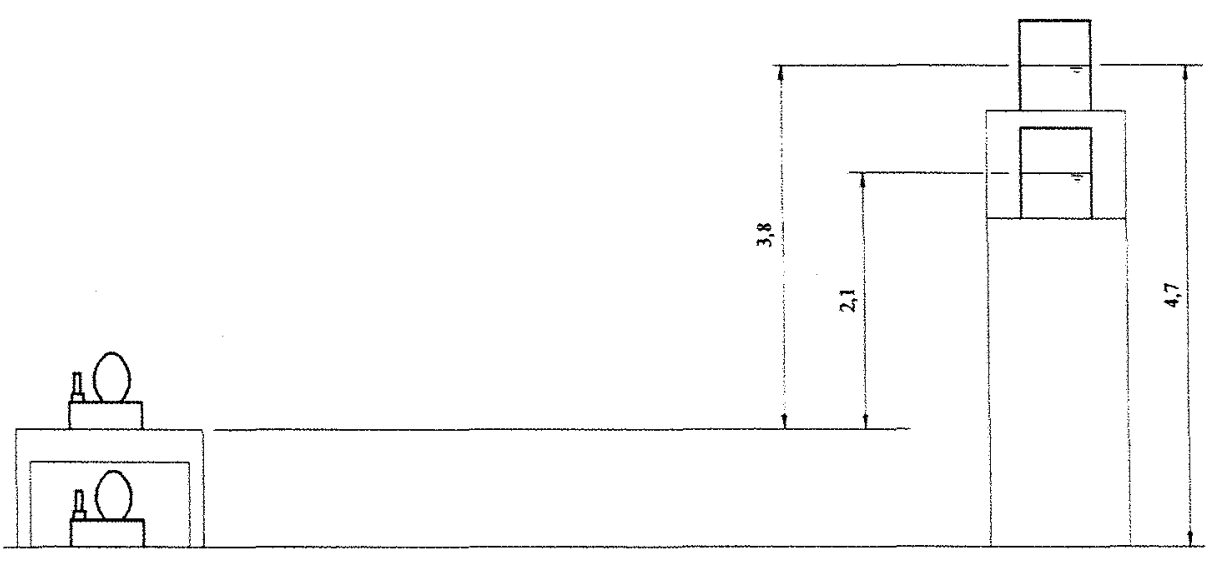

Figura 6- Esquema dos desníveis de alimentação adotados

\subsection{Comprimento e diâmetro da tubulação de alimentação}

Foi utilizado o mesmo comprimento de tubulação $(\mathrm{L}=33 \mathrm{~m})$ para os dois materiais estudados, com diâmetro interno de $0,0389 \mathrm{~m}(1$ 1/2") para a tubulação de PVC e $0,0414 \mathrm{~m}(1$ 1/2") para a tubulação de aço galvanizado. Durante todo o ensaio, manteve-se a tubulação sempre retilinea e em declive.

\subsection{Pressão de recalque}

Um manômetro digital com diâmetro de $0,1 \mathrm{~m}$, capacidade de $0-1000 \mathrm{kPa}$ e precisão de $0,5 \%$ foi instalado junto ao tanque de estabilização, que estava ligado diretamente ao carneiro hidráulico, procurando melhorar a estabilização da leitura da pressão de recalque.

A pressão gerada no interior do tanque de estabilização, quando transformada em altura de coluna de água corresponde exatamente à altura de recalque. $O$ controle da 
pressão de recalque foi feito utilizando-se do registro de saída do tanque. Assim, menores aberturas do registro correspondem a maiores pressões.

\subsection{Vazão}

Foram medidas diretamente as vazões de escape e de recalque. Para a vazão de escape, utilizou-se de um balde de $0,02 \mathrm{~m}^{3}$ e mediu-se o tempo em que o volume foi preenchido. Para vazão de recalque, cronometrou-se o tempo para obter certa quantidade de água no balde. A quantidade de água no balde foi determinada por pesagem em uma balança digital com precisão de $1 \times 10^{-3} \mathrm{~kg}$. Um registro de agulha inserido na saída do tanque de estabilização, permitiu a regulagem da vazão de recalque.

\subsection{Batidas}

Com o auxílio de um cronômetro digital, foi avaliado o número de batidas da válvula de escape no intervalo de um minuto.

\subsection{Coleta de dados}

Para cada avaliação do desempenho do carneiro hidráulico, escorvou-se a tubulação de alimentação pressionando a válvula de escape e deixando a água extravasar. Após o escorvamento do sistema, abriu-se a válvula de recalque afim de obter os pares de valores vazão e pressão.

O sistema ficou em funcionamento até a estabilização da leitura da pressão e em seguida mediu-se as vazões de recalque e de escape, pressão e batidas por minuto. Incrementou-se a vazão de recalque através do registro de agulha na saída do tanque de estabilização. 
Calculou-se o rendimento pelo método de D'Aubuisson para cada tipo da tubulação de alimentação e para cada desnível estudado. O cálculo do rendimento foi feito a partir das pressão de recalque $(H)$, vazão de escape $(Q)$, vazão de recalque $(q)$ e altura de alimentação $(\mathrm{h})$.

\subsection{Análise dos dados}

Foi feita a análise de variância para a verificação da dependência dos dados, utilizando-se o teste $t$ ao nível de $1 \%$. O valor de $\mathrm{R}^{2}$ foi o parâmetro usado para verificar o ajuste das curvas de regressão dos dados observados. Foram utilizadas duas equações para a representação dos dados: polinomial de segundo grau para as curvas de rendimento e exponencial para as curvas de pressão. 


\section{RESULTADOS E DISCUSSÃO}

Os dados obtidos foram analisados comparativamente considerando: a) o desempenho do carneiro hidráulico quando alimentado pelas tubulações de PVC e de aço galvanizado; e b) o efeito do número de batidas da válvula de escape no desempenho do carneiro hidráulico para cada material constituinte da tubulação de alimentação.

\subsection{Influência dos materiais constituintes da tubulação de alimentação}

$\mathrm{Na}$ Figura 7 são apresentados os gráficos que relacionam os dados de vazão, pressão e rendimento obtidos no recalque para cada desnível estudado.

O rendimento diz respeito ao consumo de água para alimentar o carneiro hidráulico, ou seja, quanto menor a quantidade de água necessária ao acionamento, maior será o rendimento. 

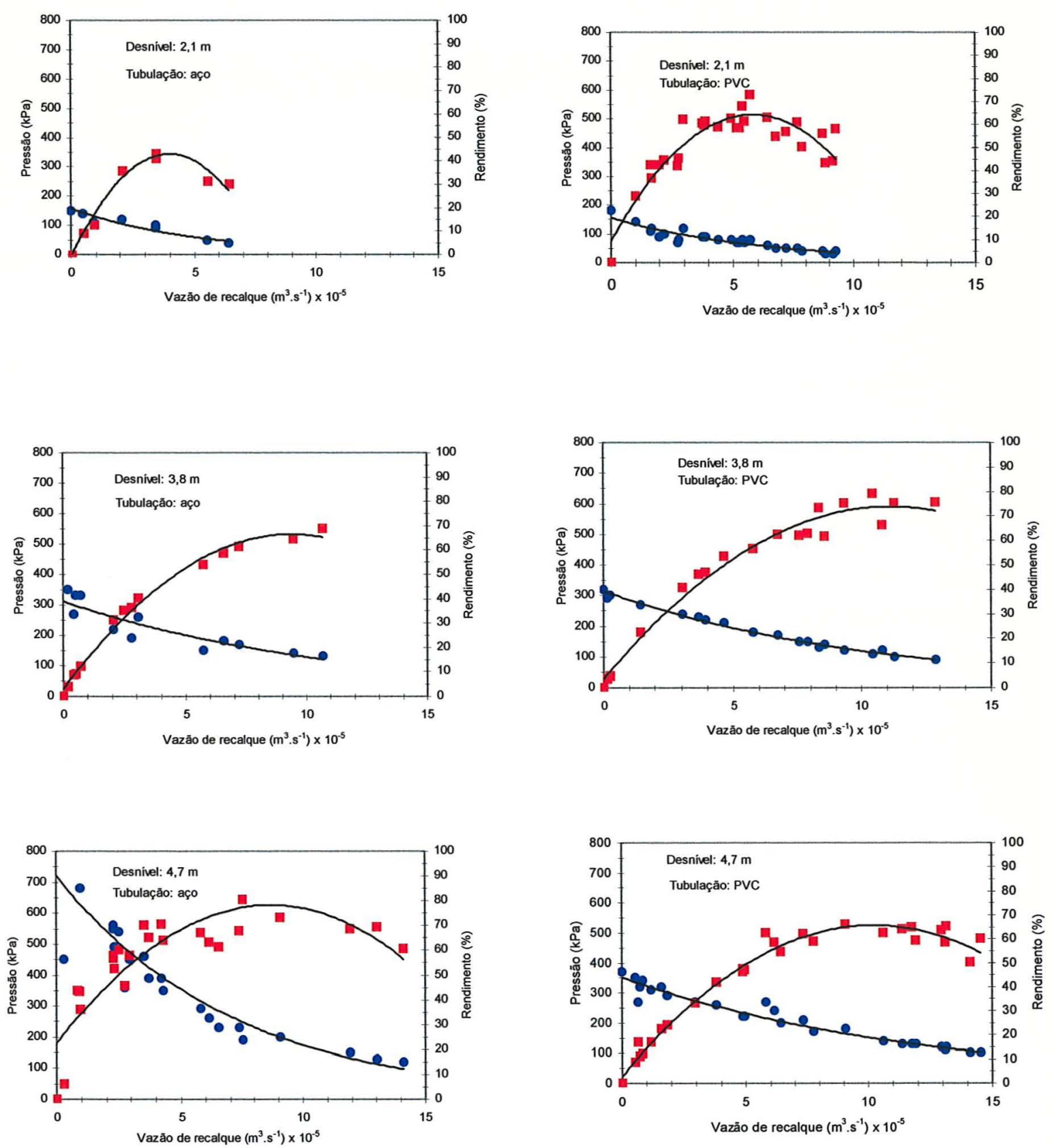

( $)^{\prime}$ Rendimento

(•) pressão

Figura 7- Rendimento e pressão em função da vazão e do desnível da tubulação de alimentação e do material constituinte 
O rendimento em função da vazão foi ajustado ao modelo expresso pela eq.

(5), obtendo-se os parâmetros apresentados na Tabela 1.

$\eta=a \cdot q^{2}+b \cdot q+c$

sendo:

$\eta$ - rendimento, $\%$

a, b e c - parâmetros da equação, adimensional

$\mathrm{q}$ - vazão de recalque, $\mathrm{m}^{3} \cdot \mathrm{s}^{-1}$

Tabela 1- Parâmetros da equação de regressão rendimento $v s$ vazão

\begin{tabular}{cccccc}
\hline Desnivel & Material & Fator a & Fator b & Fator c & $\mathrm{R}^{2}$ \\
\hline $2,1 \mathrm{~m}$ & Aço & $-27504872273,7$ & 2191800,8646 & $-0,7252$ & $0,9661^{* *}$ \\
$2,1 \mathrm{~m}$ & PVC & $-16211700610,8$ & 1887114,3946 & 9,3550 & $0,8399^{* *}$ \\
$3,8 \mathrm{~m}$ & Aço & $-7217079105,9$ & 1353889,7831 & 2,9810 & $0,9897^{* *}$ \\
$3,8 \mathrm{~m}$ & PVC & $-5677894644,5$ & 1265100,5103 & 3,3570 & $0,9728^{* *}$ \\
$4,7 \mathrm{~m}$ & Aço & $-7397692974,7$ & 1285544,3450 & 22,4730 & $0,7492^{* *}$ \\
$4,7 \mathrm{~m}$ & PVC & $-6039771607,5$ & 1231601,7883 & 2,9120 & $0,9787^{* *}$ \\
\hline
\end{tabular}

**Significativos ao nível de $1 \%$ de probabilidade

Todos os ajustes dos dados a eq. (5), foram significativos ao nível de $1 \%$ de probabilidade pelo teste $t$.

Os valores de rendimento máximo foram obtidos a partir da raiz da derivada das equaç̃es rendimento vs vazão, sendo os resultados mostrados na Tabela 2. 
Tabela 2- Rendimento máximo, pressão e vazão de recalque correspondentes para os desníveis e materiais estudados

\begin{tabular}{ccccc}
\hline Desnivel & Material & $\begin{array}{c}\text { Rendimento } \\
\text { máximo } \\
(\%)\end{array}$ & $\begin{array}{c}\text { Pressão } \\
(\mathrm{kPa})\end{array}$ & $\begin{array}{c}\text { Vazão de recalque } \\
\left(\mathrm{m}^{3} \cdot \mathrm{s}^{-1}\right)\end{array}$ \\
\hline $2,1 \mathrm{~m}$ & Aço & 42,93 & 72,19 & $3,984387 \times 10^{-5}$ \\
$2,1 \mathrm{~m}$ & PVC & 64,27 & 61,63 & $5,82022 \times 10^{-5}$ \\
$3,8 \mathrm{~m}$ & Aço & 66,47 & 135,48 & $9,37976 \times 10^{-5}$ \\
$3,8 \mathrm{~m}$ & PVC & 73,82 & 106,57 & $11,1406 \times 10^{-5}$ \\
$4,7 \mathrm{~m}$ & Aço & 78,32 & 209,71 & $8,68882 \times 10^{-5}$ \\
$4,7 \mathrm{~m}$ & PVC & 65,69 & 148,89 & $10,1958 \times 10^{-5}$ \\
\hline
\end{tabular}

Na situação de rendimento máximo, as vazões de recalque para a tubulação de alimentação de PVC foram maiores que as de aço galvanizado em todos os desníveis estudados. Quanto às pressões relacionadas ao rendimento máximo a tubulação de aço apresentou valores maiores que as da tubulação de PVC.

O rendimento máximo, de $78 \%$, ocorreu para a tubulação de aço galvanizado com o maior desnível, $4,7 \mathrm{~m}$. Nas demais condições de desnivel, a tubulação de PVC apresentou maior rendimento.

Pelos resultados apresentados, pode-se inferir que existe um limite de desnível além do qual o rendimento máximo passa da tubulação de PVC para a de aço galvanizado. Na Figura 8 mostra-se o desnível de 4,2 m como este limite.

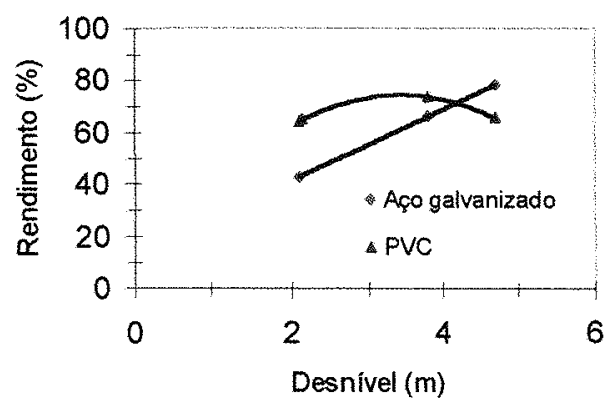

Figura 8- Rendimento vs desnível para os materiais estudados 
Uma possivel explicação para o observado é que comparativamente ao aço, a tubulação de PVC tem duas características distintas que irão influir no rendimento: uma favorável ao rendimento é a menor rugosidade interna, conduzindo a menor perda de carga, a outra, desfavorável, é a maior elasticidade da tubulação, que absorve parte do golpe de ariete produzido. Em situações de menor altura de alimentação (menor que 4,2 $\mathrm{m}$ ), portanto menor intensidade de golpe de ariete, o PVC apresentou melhor rendimento que 0 aço galvanizado, isto porque o efeito favorável da rugosidade predominou sobre 0 efeito da maior elasticidade. Para as situações de maior golpe (maior que 4,2 m) a situação se inverteu, ou seja, predominou o efeito da menor elasticidade sobre a rugosidade, levando a resultados favoráveis ao aço galvanizado, em termos de rendimento.

A pressão em função da vazão foi ajustado ao modelo da eq. (6), obtendo-se os parâmetros apresentados na Tabela 3 .

$$
P=f \cdot e^{-k \cdot q}
$$

sendo:

$\mathrm{P}$ - pressão, $\mathrm{kPa}$

f e $\mathrm{k}$ - parâmetros da equação, adimensional

$q$ - vazão, $\mathrm{m}^{3} \cdot \mathrm{s}^{-1}$

Tabela 3- Parâmetros da equação de regressão pressão vs vazão

\begin{tabular}{ccccc}
\hline Desnível & Material & Fator f & Fator $\mathrm{k}$ & $\mathrm{R}^{2}$ \\
\hline $2,1 \mathrm{~m}$ & Aço & 157,40 & 19561,0 & $0,9174^{* *}$ \\
$2,1 \mathrm{~m}$ & PVC & 155,38 & 15888,0 & $0,8901^{* *}$ \\
$3,8 \mathrm{~m}$ & Aço & 311,42 & 8872,9 & $0,8455^{* *}$ \\
$3,8 \mathrm{~m}$ & PVC & 315,07 & 9729,4 & $0,9881^{* *}$ \\
$4,7 \mathrm{~m}$ & Aço & 722,48 & 14236 & $0,8845^{* *}$ \\
$4,7 \mathrm{~m}$ & PVC & 350,56 & 8398,5 & $0,9634^{* *}$ \\
\hline
\end{tabular}

**Significativos ao nivel de $1 \%$ de probabilidade 
A pressão máxima foi obtida para vazão nula, a partir da equação correspondente a cada material e desnível estudado (Tabela 4).

Tabela 4- Pressão máxima para os desníveis e materiais estudados

\begin{tabular}{ccc}
\hline Desnivel & Material & $\begin{array}{c}\text { Pressão máxima } \\
(\mathrm{kPa})\end{array}$ \\
\hline $2,1 \mathrm{~m}$ & Aço & 157,40 \\
$2,1 \mathrm{~m}$ & PVC & 155,38 \\
$3,8 \mathrm{~m}$ & Aço & 311,42 \\
$3,8 \mathrm{~m}$ & PVC & 315,07 \\
$4,7 \mathrm{~m}$ & Aço & 722,48 \\
$4,7 \mathrm{~m}$ & PVC & 350,56 \\
\hline
\end{tabular}

Exceto para o desnivel de $3,8 \mathrm{~m}$ a tubulação de aço galvanizado apresentou maior pressão máxima, apesar da diferença entre pressões para o mesmo desnível serem pequenas, em torno de $4 \mathrm{kPa}$. Para o máximo desnivel, $4,7 \mathrm{~m}$, obteve-se grande diferença entre as pressões, em torno de $360 \mathrm{kPa}$.

\subsection{Frequência de batidas da válvula de escape}

Estudou-se o número de batidas da válvula de escape, agrupando-os em intervalos, para cada desnivel e material, analisando-se o rendimento máximo e a pressão de recalque em função da vazão correspondente.

A equação para a curva de rendimento em função da vazão de recalque foi ajustada por um modelo polinomial de segundo grau [eq. (5)] e, para a curva de pressão em função da vazão de recalque, a um modelo exponencial [eq. (6)].

Os gráficos com as curvas de rendimento vs vazão de recalque e pressão $v s$ vazão de recalque são apresentados na Figura 9. 

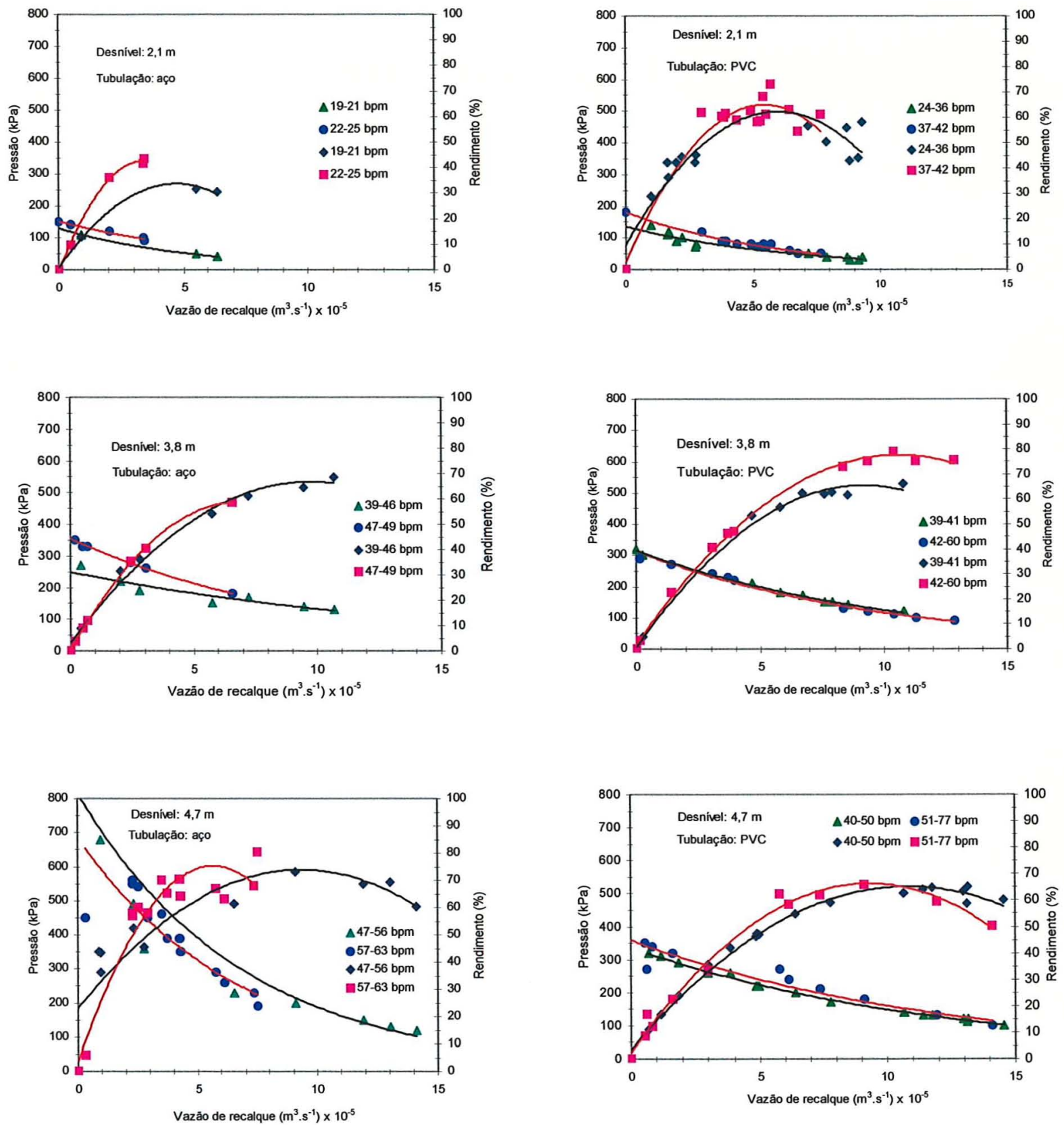

$("$,$) Rendimento \quad(\bullet, \bullet)$ Pressão

Figura 9- Rendimento e pressão em função da vazão e do desnível da tubulação de alimentação e do material constituinte 
Nas Tabelas 5 e 6 são apresentados os coeficientes das equações de rendimento e pressão vs vazão. Para todos os intervalos estudados, a regressão para o rendimento e pressão foram significativas ao nivel de $1 \%$ de probabilidade.

Tabela 5- Parâmetros da equação de regressão de rendimento vs vazão para desnivel de 2,1 m e material da tubulação de aço galvanizado

\begin{tabular}{ccccc}
\hline Intervalo & Fator a & Fator b & Fator c & $\mathrm{R}^{2}$ \\
\hline $19-21$ & $-14775676915,7953$ & 1396152,5369 & 0,7197 & $0,9954^{* *}$ \\
$22-25$ & $-36825959784,9702$ & 2525932,0477 & $-1,7152$ & $0,9974^{* *}$
\end{tabular}

**Significativos ao nível de $1 \%$ de probabilidade

Tabela 6- Parâmetros da equação de regressão de pressão vs vazão para desnivel de 2,1 m e material da tubulação de aço galvanizado

\begin{tabular}{cccc}
\hline Intervalo & Fator $\mathrm{f}$ & Fator $\mathrm{g}$ & $\mathrm{R}^{2}$ \\
\hline $19-21$ & 130,08 & 18057 & $0,9958^{* *}$ \\
$22-25$ & 150,96 & 13264 & $0,9602^{* *}$ \\
\hline
\end{tabular}

**Significativos ao nivel de $1 \%$ de probabilidade

Na Tabela 7 verificam-se os valores de rendimento máximo e respectivas vazão e pressão. Entre 22-25 batidas por minuto, o carneiro hidráulico apresentou maior rendimento e maior pressão para o rendimento máximo, e para 19-21 batidas por minuto, maior vazão de recalque para o rendimento máximo.

Tabela 7- Rendimento máximo, vazão e pressão para o rendimento máximo, utilizando tubulação de aço com desnivel de $2,1 \mathrm{~m}$

\begin{tabular}{cccc} 
Intervalo & $\begin{array}{c}\text { Rendimento } \\
\text { máximo } \\
(\%)\end{array}$ & $\begin{array}{c}\text { Vazão para rendimento } \\
\text { máximo }\left(\mathrm{m}^{3} \cdot \mathrm{s}^{-1}\right)\end{array}$ & $\begin{array}{c}\text { Pressão para o } \\
\text { rendimento máximo }\end{array}$ \\
\hline $19-21$ & 33,70 & $4,7244 \times 10^{-5}$ & $(\mathrm{kPa})$ \\
$22-25$ & 42,59 & $3,4295 \times 10^{-5}$ & 55,42 \\
\hline
\end{tabular}


Nas Tabelas 8 e 9 são apresentados os coeficientes das equações de rendimento e pressão vs vazão. Para todos os intervalos estudados, as regressões para rendimento e pressão foram significativas ao nível de $1 \%$ de probabilidade.

Tabela 8- Parâmetros da equação rendimento vs vazão para desnível de $2,1 \mathrm{~m}$ e material da tubulação de PVC

\begin{tabular}{ccccc}
\hline Intervalo & Fator a & Fator $b$ & Fator $c$ & $\mathrm{R}^{2}$ \\
\hline $24-36$ & $-14794636275,1863$ & 1764840,6106 & 9,6280 & $0,8153^{* *}$ \\
$37-42$ & $-20997725035,9286$ & 2282242,4628 & 2,8703 & $0,8999^{* *}$
\end{tabular}

**Significativos ao nivel de $1 \%$ de probabilidade

Tabela 9- Parâmetros da equação de regressão de pressão vs vazão para desnivel de 2,1 m e material da tubulação de PVC

\begin{tabular}{cccc}
\hline Intervalo & Fator $\mathrm{f}$ & Fator $\mathrm{g}$ & $\mathrm{R}^{2}$ \\
\hline $24-36$ & 135,79 & 15254 & $0,9336^{* *}$ \\
$37-42$ & 180,77 & 17189 & $0,9439 * *$ \\
\hline
\end{tabular}

**Significativos ao nível de $1 \%$ de probabilidade

$\mathrm{Na}$ Tabela 10 verificam-se os valores de rendimento máximo e respectivas vazão e pressão. Entre 37-42 batidas por minuto, o carneiro hidráulico apresentou maior rendimento e maior pressão para o rendimento máximo, e para 24-36 batidas por minuto, maior vazão de recalque para o rendimento máximo.

Tabela 10- Rendimento máximo, vazão e pressão para o rendimento máximo, utilizando tubulação de PVC com desnível de $2,1 \mathrm{~m}$

\begin{tabular}{cccc}
\hline Intervalo & $\begin{array}{c}\text { Rendimento } \\
\text { máximo } \\
(\%)\end{array}$ & $\begin{array}{c}\text { Vazão para rendimento } \\
\text { máximo }\left(\mathrm{m}^{3} \cdot \mathrm{s}^{-1}\right)\end{array}$ & $\begin{array}{c}\text { Pressão para o } \\
\text { rendimento máximo }\end{array}$ \\
\hline $24-36$ & 62,25 & $5,9644 \times 10^{-5}$ & $(\mathrm{kPa})$ \\
$37-42$ & 64,88 & $5,4345 \times 10^{-5}$ & 54,66 \\
\hline
\end{tabular}


Nas Tabelas 11 e 12 são apresentados os coeficientes das equações de rendimento e pressão $v s$ vazão. Para todos os intervalos estudados, as regressões para rendimento e pressão foram significativas ao nivel de $1 \%$ de probabilidade.

Tabela 11- Parâmetros da equação rendimento vs vazão para desnivel de $3,8 \mathrm{~m} \mathrm{e}$ material da tubulação de aço galvanizado

\begin{tabular}{ccccc}
\hline Intervalo & Fator a & Fator b & Fator c & $\mathrm{R}^{2}$ \\
\hline $39-46$ & $-6679544713,2588$ & 1302282,3364 & 3,2557 & $0,9897^{* *}$ \\
$47-49$ & $-12529716652,4316$ & 1707254,0651 & 0,4599 & $0,9997^{* *}$ \\
\hline
\end{tabular}

* *Significativos ao nível de $1 \%$ de probabilidade

Tabela 12- Parâmetros da equação de regressão de pressão $v s$ vazão para desnivel de $3,8 \mathrm{~m}$ e material da tubulação de aço galvanizado

\begin{tabular}{cccc}
\hline Intervalo & Fator $\mathrm{f}$ & Fator $\mathrm{g}$ & $\mathrm{R}^{2}$ \\
\hline $39-46$ & 248,91 & 6325,2 & $0,8841^{* *}$ \\
$47-49$ & 354,29 & 10227 & $0,9975^{* *}$
\end{tabular}

**Significativos ao nivel de $1 \%$ de probabilidade

$\mathrm{Na}$ Tabela 13 verificam-se os valores de rendimento máximo e respectivas vazão e pressão. Entre 39-46 batidas por minuto, o carneiro hidráulico apresentou maior rendimento e vazão de recalque para o rendimento máximo, e para 47-49 batidas por minuto, maior pressão para o rendimento máximo.

Tabela 13- Rendimento máximo, vazão e pressão para o rendimento máximo, utilizando tubulação de aço com desnível de $3,8 \mathrm{~m}$

\begin{tabular}{cccc}
\hline Intervalo & $\begin{array}{c}\text { Rendimento } \\
\text { máximo } \\
(\%)\end{array}$ & $\begin{array}{c}\text { Vazão para rendimento } \\
\text { máximo }\left(\mathrm{m}^{3} \cdot \mathrm{s}^{-1}\right)\end{array}$ & $\begin{array}{c}\text { Pressão para o } \\
\text { rendimento máximo }\end{array}$ \\
\hline $39-46$ & 66,73 & $9,7482 \times 10^{-5}$ & $(\mathrm{kPa})$ \\
$47-49$ & 58,61 & $6,8128 \times 10^{-5}$ & 134,35 \\
\hline
\end{tabular}


Nas Tabelas 14 e 15 são apresentados os coeficientes das equações de rendimento e pressão vs vazão. Para todos os intervalos estudados, a regressão para o rendimento e pressão foram significativas ao nivel de $1 \%$ de probabilidade.

Tabela 14- Parâmetros da equação rendimento vs vazão para desnível de $3,8 \mathrm{~m}$ e material da tubulação de PVC

\begin{tabular}{ccccc}
\hline Intervalo & Fator a & Fator b & Fator c & $\mathrm{R}^{2}$ \\
\hline $39-41$ & $-7674467942,3227$ & 1410712,1220 & 0,7268 & $0,9945^{* *}$ \\
$42-60$ & $-6742263875,2556$ & 1429824,2122 & 1,8090 & $0,9976^{* *}$ \\
\hline
\end{tabular}

${ }^{* *}$ Significativos ao nivel de $1 \%$ de probabilidade

Tabela 15- Parâmetros da equação pressão vs vazão para desnivel de $3,8 \mathrm{~m}$ e material da tubulação de PVC

\begin{tabular}{cccc}
\hline Intervalo & Fator $\mathrm{f}$ & Fator $\mathrm{g}$ & $\mathrm{R}^{2}$ \\
\hline $39-41$ & 314,83 & 9286 & $0,9952^{* *}$ \\
$42-60$ & 313,32 & 9966,4 & $0,9920^{* *}$ \\
\hline
\end{tabular}

**Significativos ao nivel de $1 \%$ de probabilidade

$\mathrm{Na}$ Tabela 16 verificam-se os valores de rendimento máximo e respectivas vazão e pressão. Entre 42-60 batidas por minuto, o cameiro hidráulico apresentou maior rendimento e vazão de recalque para o rendimento máximo, e para $39-41$ batidas por minuto, maior pressão para o rendimento máximo.

Tabela 16- Rendimento máximo, vazão e pressão para o rendimento máximo, utilizando tubulação de PVC com desnivel de $3,8 \mathrm{~m}$

\begin{tabular}{cccc}
\hline Intervalo & $\begin{array}{c}\text { Rendimento } \\
\text { máximo } \\
(\%)\end{array}$ & $\begin{array}{c}\text { Vazão para rendimento } \\
\text { máximo }\left(\mathrm{m}^{3} \cdot \mathrm{s}^{-1}\right)\end{array}$ & $\begin{array}{c}\text { Pressão para o } \\
\text { rendimento máximo } \\
(\mathrm{kPa})\end{array}$ \\
\hline $39-41$ & 65,55 & $9,1909 \times 10^{-5}$ & 134,09 \\
$42-60$ & 77,61 & $10,6034 \times 10^{-5}$ & 108,90 \\
\hline
\end{tabular}


Nas Tabelas 17 e 18 são apresentados os coeficientes das equações de rendimento e pressão vs vazão. Para todos os intervalos estudados, as regressões para rendimento e pressão foram significativas ao nível de $1 \%$ de probabilidade.

Tabela 17- Parâmetros da equação rendimento vs vazão para desnível de $4,7 \mathrm{~m}$ e material da tubulação de aço galvanizado

\begin{tabular}{ccccc}
\hline Intervalo & Fator a & Fator b & Fator c & $\mathrm{R}^{2}$ \\
\hline $47-56$ & $-5835116433,9155$ & 1089672,1353 & 23,0272 & $0,7838^{* *}$ \\
$57-63$ & $-22448467905,8531$ & 2535576,9292 & 3,7105 & $0,9081^{* *}$ \\
\hline
\end{tabular}

**Significativos ao nível de $1 \%$ de probabilidade

Tabela 18- Parâmetros da equação de regressão de pressão vs vazão para desnível de 4,7 m e material da tubulação de aço galvanizado

\begin{tabular}{cccc}
\hline Intervalo & Fator $\mathrm{f}$ & Fator $\mathrm{g}$ & $\mathrm{R}^{2}$ \\
\hline $47-56$ & 816,27 & 14692 & $0,9230^{* *}$ \\
$57-63$ & 683,87 & 14884 & $0,8341^{* *}$
\end{tabular}

**Significativos ao nível de $1 \%$ de probabilidade

$\mathrm{Na}$ Tabela 19 verificam-se os valores de rendimento máximo e respectivas vazão e pressão. Entre 57-63 batidas por minuto, o carneiro hidráulico apresentou maior rendimento e maior pressão para o rendimento máximo, e para 47-56 batidas por minuto, maior vazão de recalque para o rendimento máximo.

Tabela 19- Rendimento máximo, vazão e pressão para o rendimento máximo, utilizando tubulação de aço com desnível de $4,7 \mathrm{~m}$

\begin{tabular}{cccc}
\hline Intervalo & $\begin{array}{c}\text { Rendimento } \\
\text { máximo } \\
(\%)\end{array}$ & $\begin{array}{c}\text { Vazão para rendimento } \\
\text { máximo }\left(\mathrm{m}^{3} \cdot \mathrm{s}^{-1}\right)\end{array}$ & $\begin{array}{c}\text { Pressão para o } \\
\text { rendimento máximo } \\
(\mathrm{kPa})\end{array}$ \\
\hline $47-56$ & 73,89 & $9,3371 \times 10^{-5}$ & 207,04 \\
$57-63$ & 75,30 & $5,6475 \times 10^{-5}$ & 295,06 \\
\hline
\end{tabular}


Nas Tabelas 20 e 21 são apresentados os coeficientes das equações de rendimento e pressão vs vazão. Para todos os intervalos estudados, as regressões para rendimento e pressão foram significativas ao nível de $1 \%$ de probabilidade.

Tabela 20- Parâmetros da equação rendimento vs vazão para desnível de $4,7 \mathrm{~m} \mathrm{e}$ material da tubulação de PVC

\begin{tabular}{ccccc}
\hline Intervalo & Fator a & Fator b & Fator c & $\mathrm{R}^{2}$ \\
\hline $40-50$ & $-5286973490,6533$ & 1142267,0673 & 3,5031 & $0,9907^{* *}$ \\
$51-77$ & $-7385231157,5003$ & 1374557,3432 & 2,3084 & $0,9863^{* *}$ \\
\hline
\end{tabular}

**Significativos ao nivel de $1 \%$ de probabilidade

Tabela 21- Parâmetros da equação de regressão de pressão $v s$ vazão para desnivel de $4,7 \mathrm{~m}$ e material da tubulação de PVC

\begin{tabular}{cccc}
\hline Intervalo & Fator $\mathrm{f}$ & Fator $\mathrm{g}$ & $\mathrm{R}^{2}$ \\
\hline $40-50$ & 336,76 & 8233,1 & $0,9946^{* *}$ \\
$51-77$ & 358,67 & 8124,4 & $0,9211^{* *}$
\end{tabular}

**Significativos ao nivel de $1 \%$ de probabilidade

$\mathrm{Na}$ Tabela 22 verificam-se os valores de rendimento máximo e respectivas vazão e pressão. Entre 51-77 batidas por minuto, o carneiro hidráulico apresentou maior rendimento e maior pressão para o rendimento máximo, e para 40-50 batidas por minuto, maior vazão de recalque para o rendimento máximo.

Tabela 22- Rendimento máximo, vazão e pressão para o rendimento máximo, utilizando tubulação de PVC com desnivel de 4,7 m

\begin{tabular}{cccc}
\hline Intervalo & $\begin{array}{c}\text { Rendimento } \\
\text { máximo } \\
(\%)\end{array}$ & $\begin{array}{c}\text { Vazão para rendimento } \\
\text { máximo }\left(\mathrm{m}^{3} \cdot \mathrm{s}^{-1}\right)\end{array}$ & $\begin{array}{c}\text { Pressão para o } \\
\text { rendimento máximo } \\
(\mathrm{kPa})\end{array}$ \\
\hline $40-50$ & 65,20 & $10,802 \times 10^{-5}$ & 138,37 \\
$51-77$ & 66,26 & $9,3061 \times 10^{-5}$ & 168,39 \\
\hline
\end{tabular}


Cabe salientar que foi feito apenas uma regulagem na válvula de escape em todos os ensaios, monitorando o número de batidas em cada situação, visto que o alvo principal do presente trabalho foi avaliar os dois diferentes materiais. Observou-se que houve influência do número de batidas no desempenho de um carneiro hidráulico, porém este se deu de modo aparentemente independente dos parâmetros estudados. Para melhor conhecimento da influência do número de batidas no desempenho de um carneiro hidráulico, novos estudos variando a regulagem da válvula de escape deverão ser conduzidas. 


\section{CONCLUSÕES}

No presente trabalho analisou-se o desempenho do carneiro hidráulico alimentado por tubulações de PVC e de aço galvanizado, concluindo-se que o rendimento máximo com o carneiro hidráulico utilizando-se de tubulação alimentadora de PVC é obtido com até 4,2 m de desnível; além desse valor a tubulação de aço galvanizado é mais eficiente. Há influência do número de batidas da válvula de escape no desempenho de um carneiro hidráulico. 


\section{REFERÊNCIAS BIBLIOGRÁFICAS}

AQUA ENVIRONMENT CO. Hydraulic water rams: catalogue. Bolina, 1997. 4p.

BC Livestock Watering. Hydraulic Ram. http://www.bc.ducks.ca/fs/watering/ hydraulic.htm. (29 Mar 2000).

BHOI, K.L.; RAM S.; CHAUHAN. H.S. Field evaluation of hydraulic rams. ICID Bulletin, v.43, p.105-116, 1994.

CARRASCO, J.E.H. Fabricación, venta e instalación de Arietes Hidráulicos. Santiago de Chile. http://www.business.fortunccity.com/greenberg/558/index.html. (29 Mar 2000).

CORVALÁN, A.; GÁLVEZ. R. Bomba de ariete hidráulico. http://www.cipres.cec. uchile.cl/ rgalvez/bomba.htm. (29 Mar 2000).

DAKER, A. A água na agricultura: captação, elevação e melhoramento da água. 3.ed. Rio de Janeiro: Freitas Bastos, v.2, 1970. 304p.

DAS, K.C.; SHARMA, K.N.; PANIGRAHI, B.; SHARMA, S.D. Effect of magnification factor, supply conditions and valve clearence on performance of an hydraulic ram. In: INTERNATIONAL CONGRESS ON AGRICULTURAL ENGINEERING, 11., Dublin, 1989. Proceedings. Rotterdam: A. A. Balkema, 1989. p.721-725. 
FLEMNG, R.H. History of the hydraulic ram. http://www.theramcompany.com /history.html. (29 Mar 2000).

GRIFFIN, J. The motorless water pump. http://www.gravi-check.com/html. (29 Mar 2000).

HORNE, B.; NEWMAN, C. Hydraulic ram. The Centre for Alternative Technology. http://www.cat.org.uk/information/tipsheets/hydram.html. (29 Mar 2000).

JEFFERY, T.D.; THOMAS, T.H; SMITH, A.V.; GLOVER, P.B.; FOUNTAN, P.D. A guide to ram pump water supply systems. London: Intermediate Technology Publication, 1992. 135p.

JENNINGS, G.D. Hydraulic ram pumps. s.l: North Carolina Cooperative Extension Service, 1996. (EBAE 161-92).

KITANI, K; WILLARDSON, L.S. Hydraulic ram use for sprinkle irrigation. Transaction of the ASAE, v.27, p.1788-1791, 1984.

KROL, J. The automatic hydraulic ram: its theory and design. New York: ASME, 1976. 12p. (Paper 76-DE-17).

LIFEWATER. Hydraulic ram pumps. http:/www.lifewater.ca/ram/ram pump.htm (29 Mar 2000).

LIFEWATER INTERNATIONAL. Designing a hydraulic ram pump. http://www.lifewater.org/wfw/rws4/rws4d5.htm. (29 Mar 2000).

LINSLEY, R.K.; FRANZINI, J.B. Water resources engineering. New York: Mc Graw-Hill International. 4.ed., 1992. cap.12, p.432-433. 
MACINTYRE, A.J. Bombas e instalações de bombeamento. 2.ed. Rio de Janeiro: Ed. Guanabara Dois, 1980.

NETTO, J.M.deA. Golpe de Ariete. In: ZAMBEL, A.R. Manual de aparelhos de bombeamento de água. São Carlos: USP/EESC, 1969. cap.10, p.183-209.

ROOS, R.; ZWIENINK, S.; BATS, B. Ram pumps. http://snt.student.utwente.nl / wot/water/waterram.htm. (29 Mar 2000).

THOMAS, T. Disseminating ram-pump technology. In: PICKFORD, J.(Ed.) Affordable water supply and santitation. Leicestershire: Loughborough University, 1994. /20. WEDC CONFERENCE, 1994 - Proceedings/.

ZAMBEL, A. Z. Classificação dos aparelhos de bombeamento de água. In: ZAMBEL, A. R.. Manual de aparelhos de bombeamento de água. São Carlos: USP/EESC, cap.2, 1969 p.183-209.

ZANINI, J.R.; BEDUSCHI, L.C. Elevação de água por aríete hidráulico e bomba de pistão acionada por roda d'água. Jaboticabal: UNESP/FCAV, Depto. de Engenharia Rural, 1991. 58p. 